\title{
Protected areas in Chile: are we managing them?
}

Ignacio J. Petit ${ }^{1,4}$, Ana N. Campoy ${ }^{1,5}$, Maria-Jose Hevia ${ }^{2}$, Carlos F. Gaymer ${ }^{1,4,5^{*}}$ and Francisco A. Squeo $3,5,6$

\begin{abstract}
Background: Human population growth since the mid-1900s has been accompanied by an unsustainable use of natural resources and a corresponding impact on terrestrial and marine biota. In response, most states have established protected areas as tools to decrease biodiversity loss, being Chile one of the signatories of international conservation agreements such as the Convention on Biological Diversity (CBD) and the 2010 Aichi Targets. This study reviews the Chilean protected areas that have been created to date, with an emphasis on the existence and effectiveness of management plans for all terrestrial and marine protected areas.

Effectiveness was individually evaluated using two filters: 1) the age of the management plan and 2) the first four steps of the Protected Areas Management Effectiveness (PAME) methodology recommended by the IUCN.

Results: We show that 84 out of a total of 145 protected areas (PAs), and only five out of a total of 20 marine protected areas (MPAs), have management plans. Only 12\% $(N=16)$ of PAs are effectively managed; while in the marine realm, no MPA has an effective plan.

Conclusions: Our results show the lack of both the effectiveness of and updates to the management plans for the vast majority of the national territory and raise the following question: is it sustainable to continue adding protected areas to the national system even though it is clear that the existing support is insufficient to meet the minimum requirements for full implementation?
\end{abstract}

Keywords: AICHI targets, Biodiversity, Conservation, Chile, Effective management, MPA

\section{Background}

Since the mid-twentieth century, the global population has multiplied more rapidly than ever before; from 1950 to 2016, the human population grew from 2.5 to more than 7.3 billion people [5]. Past, current and expected future impacts of modern human activities on both terrestrial and marine environments have led to increased concern by governments and citizens. The trajectory of our civilization is having profound effects on biodiversity and an indelible footprint that is generating unprecedented changes in the history of the planet $[1,18,31]$. In the case of terrestrial ecosystems, land-use change is the most significant driver of biodiversity loss, whereas overexploitation has led to a dramatic decline

\footnotetext{
* Correspondence: cgaymer@ucn.cl

'Departamento de Biología Marina, Universidad Católica del Norte, Larrondo 1281, Coquimbo, Chile

${ }^{4}$ Millennium Nucleus for Ecology and Sustainable Management of Oceanic Islands (ESMOI), Coquimbo, Chile

Full list of author information is available at the end of the article
}

in marine biodiversity primarily due to the depletion of most fisheries worldwide [28, 31]. However, it was not until 1992 with the United Nations Conference on Environment and Development (UNCED) (also known as the Rio de Janeiro Earth Summit) that the concept of biological conservation was formally established [16] as a topic of political discourse and an unified goal for the signatories to the treaty, who aimed to reduce the impact of the human population on ecosystems, using protected areas (PAs) as one of the main tools [12, 18, 22, 31].

According to the International Union for Conservation of Nature (IUCN), a protected area (PA) is "a clearly defined geographical space, recognized, dedicated and managed, through legal or other effective means, to achieve the long-term conservation of nature with associated ecosystem services and cultural values." Protected areas are established by institutions and governments for a wide range of purposes including protecting biodiversity, maintaining ecosystem services, restoring fisheries 
stocks, managing other economic activities, minimizing conflicts among resource users and decreasing poverty [1]. If well designed and effectively managed, a PA can generate benefits with direct, immediate or delayed economic and social value in addition to those related to its conservation value [27]. This wider view of protected areas as an important tool for fostering sustainability and as playing a vital role in biodiversity conservation was acknowledged over 10 years ago at the 5th IUCN World Parks Congress, which was entitled "Benefits beyond Boundaries" [27]. More recently, marine protected areas (MPAs) have been viewed as opportunities to align conservation and development goals, resulting in potential win-win scenarios for sustainable development [22].

In 2006 (updated in 2010), the International Convention on Biological Diversity (CBD) made an international commitment to conserve "at least 17 per cent of terrestrial and inland waters, and 10 per cent of coastal and marine areas, (...) through effectively and equitably managed, ecologically representative and well-connected systems of protected areas (...) by 2020," which is known as Aichi Target 11 [4]. Following this declaration, the number of PAs increased in the subsequent years to the present, resulting in more than 10 million $\mathrm{km}^{2}$ of MPAs worldwide and a $360 \%$ growth in only 10 years $[1,18,19,22,33]$. For example, the 1.1 million-km² Marae Moana: Cook Islands Marine Park, which was created in 2012, as well as the 1.3 million- $\mathrm{km}^{2}$ Parc naturel de la mer de Corail in 2014 and the more recent (2015) 500,000- $\mathrm{km}^{2}$ Palau National Marine Sanctuary. This trend is also observable in Chile, where the largest MPAs in South America, the Motu Motiro Hiva Marine Park $\left(150,000 \mathrm{~km}^{2}\right)$ and the NazcaDesventuradas Marine Park (300,035 km²), were created in 2010 and 2016, respectively. This rapid increasing in large-scale MPAs in recent years has allowed nations to join international conservation agreements, whether geo-political or ecological, to meet self-imposed protection targets.

According to the Protected Planet Report 2016 [34], $14.7 \%$ of the global terrestrial environment (including inland waters), $4.12 \%$ of the global ocean and $10.1 \%$ of the marine realm within national jurisdictional waters have protected status. In Chile, $19.5 \%$ of the territory and $13.6 \%$ of its economic exclusive zone (EEZ) (of which $98 \%$ is represented by the Motu Motiro Hiva and Nazca-Desventuradas Marine Parks) are protected [25]. In addition, during the recent International Marine Protected Areas Congress (IMPAC4 2017) in Chile, the Chilean government committed to add three new Marine Parks in Patagonia (Cape Horn), Rapa Nui, and the Juan Fernandez Archipelago. If they are decreed, $45 \%$ of the Chilean EEZ will be protected.

Considering that the protection percentages established by Aichi Target 11 have already been reached, main concerns are whether Chile has fully met Target
11. Is the total amount of protected territory, both marine and terrestrial, representing different ecosystems well? Is it being effectively managed? Or otherwise is Chile just reaching numbers without a proper assessment of how the protected territory is being administrated? Without an accurate administration (i.e. management plans, funding, governance, etc.), these protected figures fall into the paper parks category [2], which describe a relevant worldwide problem of countries that nowadays are rapidly increasing its protected territory. Although based in a small sample size, some assessments indicate that most protected areas (76\%) have only basic management or major deficiencies, while only $24 \%$ have sound management $[17,20]$. Moreover, by 2015 only $17.5 \%$ of countries had completed and reported at least one Management Effectiveness assessment for $60 \%$ of their protected areas [34].

The aim of the present work is to evaluate the existence of management plans and their effectiveness for the designated terrestrial and marine protected areas in Chile. This study contributes to a better understanding of the actual status of the network of Chilean protected areas and assesses its greatest gaps, limitations and strengths to direct future research efforts, such as establishing a policy for action.

\section{Methods}

To assess the protection of the territory and the effectiveness of the management plans, we reviewed all the information (protected area declarations, management plans and total surface coverage of each protected area) contained in the Registry of Protected Areas of the Ministry of Environment of Chile, the latter of which was complemented by the Registry of the National Forestry Service (CONAF) and the Undersecretary of Fisheries (SUBPESCA). We included all the protected area categories recognized in the Wild Protected Areas National System (SNASPE) in our analysis, i.e., National Park (IUCN category II), National Reserve (IUCN categories IV and VI), Natural Monument (IUCN category III) and Natural Sanctuary (IUCN categories III and V), as well as those in the Fisheries and Aquaculture General Law (FAGL), i.e., Marine Park (IUCN category Ia), Marine Reserve (IUCN category IV and VI), Multiple Use Coastal Marine Protected Area (IUCN category VI) and Natural Sanctuary (IUCN categories III and V) [25].

The effectiveness of the existing management plans for each protected area was determined based on two basic criteria (used as filters). First, the last official document published as a management plan was evaluated, and it was considered obsolete if it was older than 10 years and no revision was in place. Second, documents that passed the "last official document" filter were analyzed according to the criteria of the first four steps of the IUCN- 
WCPA effectiveness framework (Protected Areas Management Effectiveness, PAME): a system for protected area management effectiveness evaluations based around six elements: context, planning, inputs, processes, outputs and outcomes (see [13] for a full explanation of the whole process of PAs management effectiveness evaluation and detailed examples). The two last steps (Outputs and Outcomes) were not included in this study due to lack of available information.

\section{Results}

There are a total of 165 protected areas in Chile, of which 145 are terrestrial, hereafter called protected areas (PAs), and the remaining 20 are in the ocean, i.e., marine protected areas (MPAs) (Additional file 1). Collectively, the 145 PAs in Chile cover $151,465 \mathrm{~km}^{2}$ or $19.5 \%$ of the country, and among them, $84\left(58 \%, 120,660 \mathrm{~km}^{2}\right)$ have a management plan (Fig. 1). The corresponding protection categories are National Parks (NPs, $N=36$ ), National Reserves (NRs, $N=48$ ), National Monuments (NMs, $N=16$ ) and Nature Sanctuaries (NSs, $N=44$ ) (Fig. 2a).

The 20 MPAs represent more than $463,000 \mathrm{~km}^{2}$ (13.6\% of the Chilean EEZ) and include the following protection categories: Coastal Marine Protected Areas (CMPAs, $N=10$ ), Marine Parks (MPs, $N=8$ ), Marine Reserves (MRs, $N=5$ ), and Nature Sanctuaries (NSs, $N$ =2). All Marine Reserves ("La Rinconada", "Isla Chañaral", "Isla Choros-Damas", "Pullinque" and "Putemún"), which correspond to $78.11 \mathrm{~km}^{2}$ (Fig. 1), have management plans, but they only represent $0.1 \%$ of the total MPA surface area. Thus, $99.9 \%$ of the MPA surface area, corresponding to CMPAs, MPs, and NSs, is not associated with a management plan (Fig. $2 \mathrm{~b}$ ).

According to our analysis, $12.41 \%$ of the PAs in Chile have an effective management plan in place, but none of the MPAs are effective managed. Therefore, only a
$10.91 \%$ of the total are under protection in Chile is being effectively managed. Considering PAs and MPAs with management plans (a total of 89), 33 passed the first effectiveness filter, i.e., four of the five existing management plans for MPAs and 29 of the 84 on land. For the second filter, 18 management plans, all of which were terrestrial, fulfilled the requirements of our analysis to be considered effective (Fig. 3).

\section{Discussion}

With the declaration of the Nazca-Desventuradas Marine Park in 2016, 13.6\% of the EEZ is now protected, which added to the $19.5 \%$ protection of the land, satisfies the commitment under the CDB Aichi Target 11 (17\% of terrestrial and inland water areas and $10 \%$ of coastal and marine areas). However, despite these promising numbers, Target 11 also requires that areas are "conserved through effectively and equitably managed, ecologically representative and well-connected systems of protected areas and other effective area-based conservation measures...". The results of the present work show that Chile remains far from reaching this international commitment, which is set for 2020, as just 84 of the 145 PAs and only five of the 20 MPAs are being managed. This is a recurrent problem and a subject of analysis worldwide as evidenced by the increasing number of publications focused on studying the real capacities and shortcomings of the governments that have subscribed to the CBD agreements to properly manage their protected land and marine territories $[1,2,6,10,14,15,18-20,30,36]$.

Even though the Aichi Targets encourage a holistic approach to biodiversity conservation, in which the land and sea is viewed as an interconnected ecosystem [34], the differences among the PAs and MPAs in Chile in terms of coverage, representativeness and management are abysmal [32]. As an example, the Malleco Forest

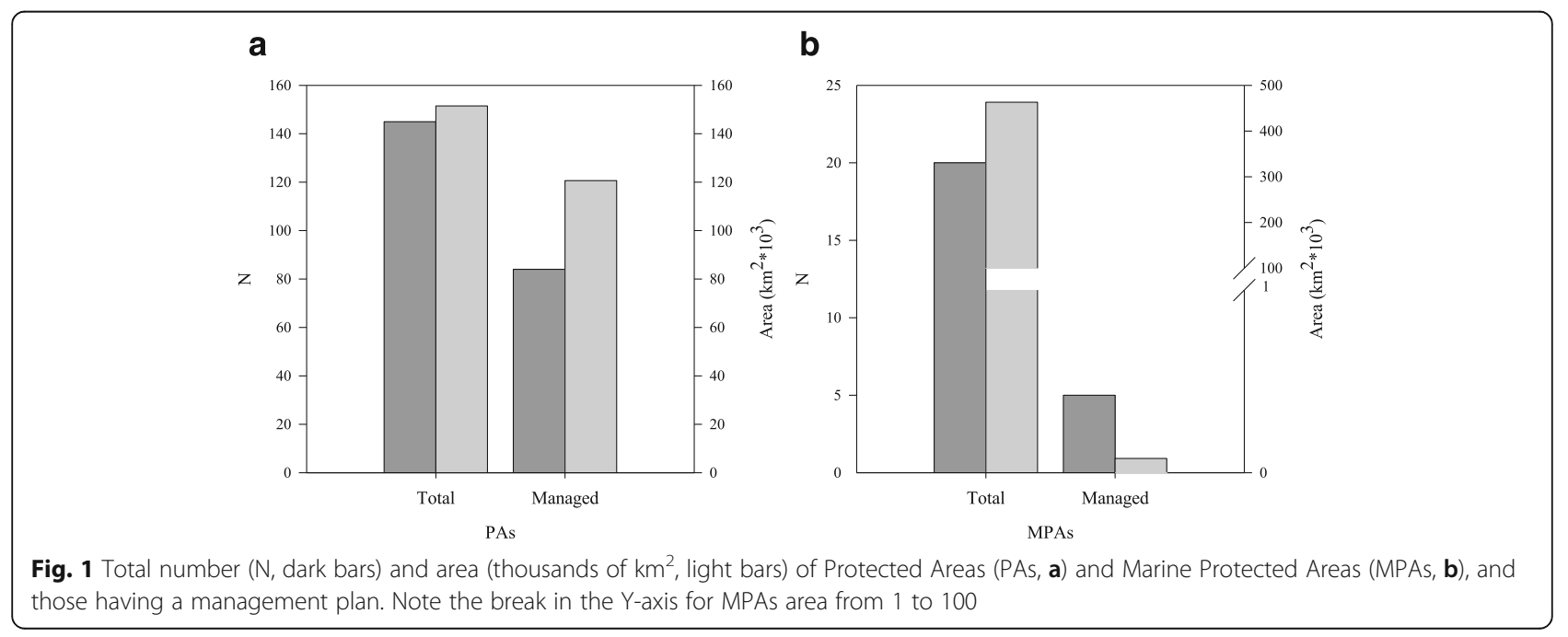



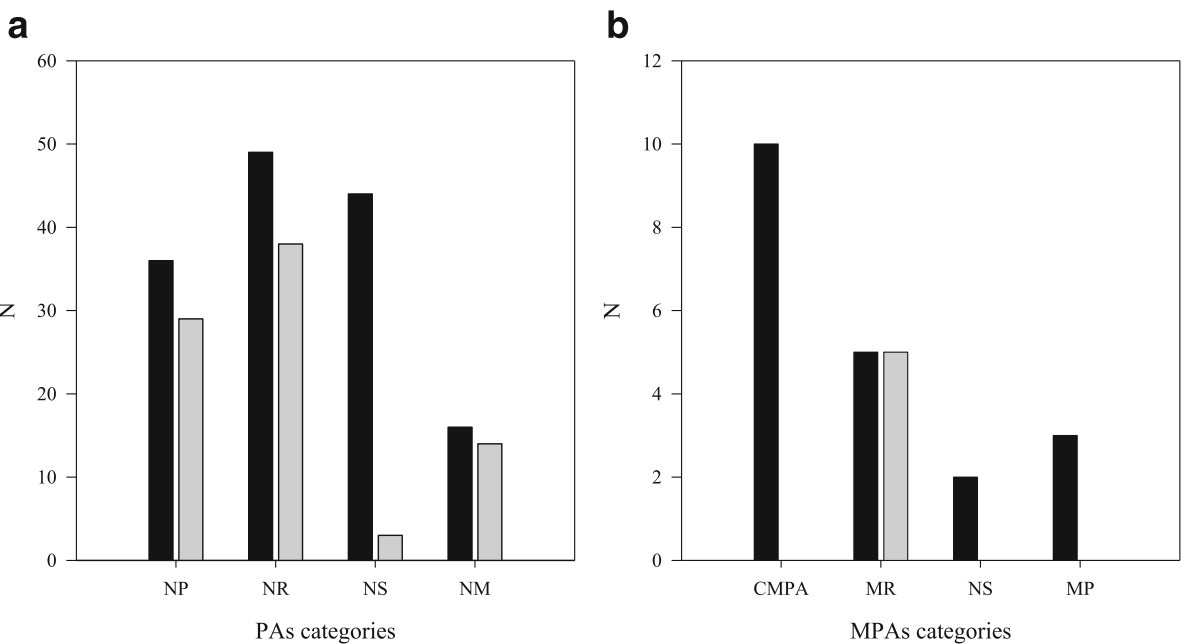

Fig. 2 Protected Areas (a) and Marine Protected Areas (b) divided by category of protection (NP: National Park, NR: National Reserve, NM: National Monument, NS: Nature Sanctuary, MR: Marine Reserve, CMPA: Coastal Marine protected Area, MP: Marine Park) without (black bars) and with (gray bars) a management plan. Categories are shown from left to right in an increasing order of restriction

Reserve was created in 1907 as the first terrestrial protected area in Chile, but it was not until 1997, almost a century later, that the first marine protected area ( $\mathrm{La}$ Rinconada MR) was established [16]. Thus, since there is a longer history of protection on land, the practice of creating management plans is also older. This is clearly reflected in that $79.66 \%$ of the total protected land area is under a management plan, but this is the case for only $0.017 \%$ of the ocean area under protection, i.e., only five Marine Reserves. This has probably also been influenced by the resource-based goals of the first Chilean MPAs, which focused on protecting the giant mussel (Choromitylus chorus) at Putemún MR, the Chilean oyster (Tiostrea chilensis) at Pullinque MR, and the northern scallop (Argopecten purpuratus) at La Rinconada MR to sustain

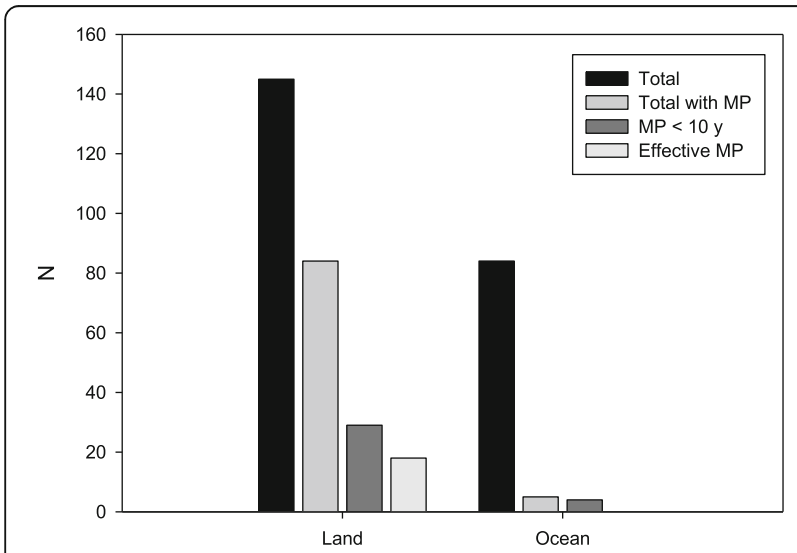

Fig. 3 Terrestrial (land) and Marine (ocean) Protected Areas with a management plan (MP): total, total with MP, MP younger than $10 \mathrm{y}$ (i.e. passed filter 1) and effective MP (i.e. passed filter 2). Note that values for land are from 0 to 300 (left $y$-axis), while for the ocean are from o to 50 (right $y$-axis) economic activity instead of preserving ecological value. It was not until 2007 that the first management plan for an MPA was developed in Chile for the Islas ChorosDamas Marine Reserve, which was based on the methodology used for the national parks in France, specifically the Port-Cros National Park [8], and implementation only began in 2017.

Furthermore, the Chilean marine area under protection is more than three times larger than the total terrestrial area under protection $(463,115 \mathrm{~km} 2$ vs $151,466 \mathrm{~km} 2)$, but there is an enormous asymmetry in the representativeness of the protected marine ecoregions as most of the marine area is covered by two large-scale marine parks, NazcaDesventuradas with $300,035 \mathrm{~km} 2$ in the Desventuradas Ecoregion and Motu Motiro Hiva with 150,000 km2 in the Easter Island Ecoregion, both of which are located around remote, uninhabited oceanic islands in the Chilean Pacific territory. Less than $1 \%$ of the other six marine ecoregions, which largely correspond to continental Chile (except for Juan Fernández), are protected [16, 32]. This is not the case for terrestrial protection since the SNASPE (Wild Protected Areas National System) includes 145 protection zones distributed throughout the country, representing most terrestrial ecosystems in different proportions [25]. Martinez-Tillería [23] showed that only three of 12 terrestrial ecoregions satisfy the $17 \%$ conservation goal; among the most unrepresented (less than 1\% under protection) terrestrial ecoregions are the Chilean Matorral and Central Andean Puna, both of which have high levels of biodiversity and endemism [32].

One of the reasons for the above mentioned asymmetry in marine ecoregions is that remote uninhabited regions are subjected to a low level of use and, consequently, have low potential for conflicts among stakeholders in contrast 
to heavily used and populated coastal areas [36]. Continental Chile has large coastal cities, fishing, mining and salmon farming, among other heavy-impact economical activities, which makes conservation of biodiversity an extremely difficult task [32]. Leenhardt et al. [19] suggested that large-scale marine protected areas (LSMPAs) became a popular conservation tool for governments during the last decade due to their appearance as a solution for reaching conservation targets. This, combined with the low level of use compared to continents, make oceanic ecoregions the best candidates for reaching the $10 \%$ global target even though representativeness is low. At the global scale, just $36 \%$ of all marine ecoregions $(N=232)$ have at least $10 \%$ of their area under protection [34]. This situation is detrimental in terms of misdirecting conservation efforts and the consequent loss of biodiversity, but it also directly affects the objectives (e.g., maintaining large-scale ecosystem services, protecting the home ranges of large migratory species, etc.) of contributing to the collective functioning of the global protected area network [30].

The picture was even worse when the effectiveness of the existent management plans was evaluated, since only a $22.2 \%$ of the plans and none of the marine plans were effective. On land, this was due, in part, to the age of the plans as $64.2 \%$ (5\% in the ocean) were older than 10 years, so we assumed that they have not been revised since initially being proposed. This means that the boundaries of the actual PAs as well as the activities and regulations implemented to reach the conservation goals in each area may be outdated. Although there is little literature on the appropriate time to revise management plans, methodologies and manuals for the design and management of LSMPAs around the world indicate that management plans should be revised every 5 years to respond to changes in the initial conditions or emergent threats (e.g., a major environmental disaster) in a timely manner [21].

One hundred percent $(N=16)$ of the terrestrial management plans that successfully passed the two effectiveness criteria used as filters corresponded to plans created in 2014 using the Technical Manual $\mathrm{N}^{\circ} 23$ "Method for Planning the Management of Protected Areas" by CONAF. It is important to emphasize that this manual significantly improved the effectiveness of management plans, but exhaustive work is still necessary for this effectiveness and efficiency to extend through all six steps (Context, Planning, Inputs, Processes, Outputs and Outcomes) of the IUCN-WCPA framework [13, 34]. Integrating the Outputs and Outcomes steps would allow each protected area to be evaluated based on the results after its creation and would answer key questions such as "What did we do and what products or services were produced?" and "What did we achieve?" This would assess whether managers and stakeholders were able to achieve the established priority goals in addition to measuring the actual effectiveness of the management actions in fulfilling the conservation objectives on which the establishment of the area was based [13].

Of the 16 management plans classified as effective, one corresponds to the Juan Fernández Archipelago (oceanic islands in central Chile), two to central Chile (VII Region) and the other 13 to southern Chile, leaving the central zone (described as one of the 25 "hotspots of global biodiversity" [26]) and the north of the country almost without any effective protection. For example, Pingüino de Humboldt NR and Los Flamencos NR, two of the most important protected areas in the central and northern areas of the country, received 53,294 and 310,698 visitors, respectively, during 2015 (in the second case, the maximum number of visitors allowed by the SNASPE), and neither were classified as being effectively managed according to our methodology. Considering Aichi Target 11, conservation must be performed in an effective, equitable and efficient manner, so this objective has not been met in much of the country.

Our analysis only incorporates the first four steps of the PAME methodology and was focused on scrutinizing the management plans for each area as opposed to directly measuring the effectiveness of this management approach in reducing biodiversity loss or the evolution of conservation objectives. Nevertheless, this methodology is still a good indirect approach for understanding the administrative and biodiversity reality of the national PA network by contrasting the local scenario with the international context. Coad et al. [6] indicated that the number of effectiveness assessments of management plans around the world increased drastically between 1990 and 2014, but UNEP-WCMC \& IUCN [34] showed that only $17.5 \%$ of participating countries had reached the target by February 2015. This indicates that most of the PAs in Chile and worldwide, both terrestrial and marine, may not be achieving their initial goals or that they were not correctly assessed a priori.

One of the main restrictions to management and thus the full implementation of protected areas may be financial support [14]. Waldron et al. [35] indicated that Chile is among the 10 most underfunded countries for biodiversity conservation in the world, and this status is shared with developing and underdeveloped countries such as Malaysia, Iraq and Senegal. Specifically, a 2016 report by the Organization for Economic Cooperation and Development (OECD) indicated that only US\$1.3 per hectare were invested for protection in Chile, a quantity that is significantly lower compared to other South American countries such as Argentina (US\$10), Colombia and Brazil (US\$4). However, although funding is considered the greatest obstacle, it is not always clear that this is the case in Chile. Figueroa [7] estimated that 
adding US\$35 million to the SNASPE per year would result in more effective management and monitoring of protected areas, but a simple analysis indicates that this is not the only key to solve the problem. Considering only the territory on land, the correlation between the amount of money designated for 68 protected areas in the SNASPE in 2016 versus the number of visitors and management plans for each creates a confusing picture. According to our criteria, only 11 PAs of the 68 analyzed have an effective management plan, but none receive more than 27,000 visitors per year in 2016 and they account for only $8.18 \%$ of the total allocated funds. In contrast, the second most visited protected area, Torres del Paine NP, received more than 200,000 visitors and more than US\$2,527,900 per year in 2016, which represents $15.29 \%$ of the total funds raised by the entire SNASPE. However, this PA did not pass any of the effectiveness filters. Therefore, funding should not be considered the main obstacle to reach effectiveness, but instead a deficient level of organization. For example, Batista \& Cabral [1] found that the highest levels of effectiveness in MPAs in South-Western Europe were due to factors such as high stakeholder participation, well-defined objectives and high levels of funding oversight.

In the SNASPE, the administration of each unit is based on a historical basis, underestimating the need for management plans updates, this not been considered an intrinsic activity of the PA management, thus needing for special funds and extra time allocation for the personnel. In the marine realm, MPAs are not only a recent tool, but they also originally started with a resource-based focus [16]. Moreover, the governance system is characterized by several sectoral agencies, not necessarily coordinated, that overlap in the ultimate goal of marine conservation [3]. This is a key limitation to e.g. implementation of ecosystem-based management in Chile, but also means that use of funds is not efficient, by duplicating actions. A new Biodiversity and Protected Areas Service (SBAP), as a coordinating entity of all terrestrial and marine protected areas could help for the solution, by avoiding discoordination and including the update of the management plans as one of its priority tasks. However, this long-time wanted project is still in the Chilean Parliament with no clear date for implementation [32].

Considering all the protected areas in Chile, the vast majority of management plans were considered null (older than 10 year, 61.6\%) or deficient (not effective, $17.4 \%$ ), which placed them in the internationally recognized category of "Paper Parks" [2]. One strategy that could help to solve this problem is a reappraisal of the existing protected areas, particularly the older ones, followed by the generation of adaptive and updated management plans because the protection targets for each conservation object may have changed. This will also require collaboration among the stakeholders, NGOs, donors, scientists, international partners and every institution working in the area to establish a shared vision to optimize procedures and consequently achieve results. The focus of the National Protected Areas Administration System must be on generating long-term and large-scale biological conservation strategies, which requires contemplation of the entire national territory as a great reservoir of biodiversity, leaving behind the concept of PAs as isolated areas and instead considering the entire Chilean PA network [16, 30, 32, 34]. Only in this way will local and global targets be achieved, effectively contributing to the preservation of different-scale conservation goals (e.g., ecosystems, biodiversity hotspots, ecosystem services, habitats, endangered species, highly migratory species, high-trophic-level species, target fisheries specie, etc.).

Because of the remoteness of some ocean territories and the great challenge of effectively implementing LSMPAs, a question arises as to whether this type of protection is really feasible in countries such as Chile that have large and remote ocean territories, limited resources, and no experience in their effective management. Major threats to biodiversity such as climate change, land-use change, overexploitation, habitat destruction and invasive species are occurring at regional and global scales. Therefore, despite the difficulty in their implementation, LSMPA networks are the appropriately sized tools for dealing with macro-scale threats to biodiversity as opposed to small-scale PAs. Thus, if large-scale protected areas are effectively managed, in combination with international scientific-political cooperation, and designed with a global perspective, they would provide knowledge of and solutions to the effects of human activities on global biodiversity. The LSMPA trend in Chile is recent, starting with Motu Motiro Hiva Marine Park in 2010. Further promising advances are being made as the Nazca-Desventuradas Marine Park is now the first LSMPA in Chile to have a management plan, proposed only 20 months after the area declaration [9].

It is clear and well understood that the establishment of new protected areas is fundamental to "ensure normal evolutionary processes occurring in a functional ecological scenario" [31] and this should incorporate Systematic Conservation Planning to avoid any bias [24, 32]. However, in the Chilean context, it is very important to consider the actual national scenario and the investment available for conservation (e.g., limited funds, inadequate administrative structure, etc.) before continuing adding protected areas to the national system without a good assessment of threats and needs, especially when support for the existing areas is insufficient to satisfy basic requirements (e.g., enforcement, management plans, rangers, outreach activities, etc.). It is fundamental that the Chilean 
government evaluates the performance of protected areas respect to their original objectives, including effective management. This could be facilitated by a collaborative work with different stakeholders to put PAs in a local context and promote the engagement of local communities in nature conservation and management. Locally managed MPAs by municipalities, local organizations or foundations could be a way to cope with this major gap. The Locally Managed Marine Areas (LMMAs) in the Pacific Islands could work as a successful example for communities for conserving their resources through communitybased management $[11,29]$.

On the other hand, it is urgent that governments around the world take action to diminish the human footprint on the planet and meet international conservation targets. It is our obligation not only to maintain each element of the biodiversity that surrounds us but also to ensure a better future for coming generations. It is time to admit and embrace the idea that the economic development of a country must go hand in hand with the conservation of its natural heritage to ensure its protection over the long term. In this way, Chile could keep being positioned as an example of conservation worldwide.

\section{Conclusions}

The present study shows the lack of both the effectiveness of and updates to the existent management plans for the vast majority of the national territory and raise the following question: is it sustainable to continue adding protected areas to the national system even though it is clear that the existing support is insufficient to meet the minimum requirements for full implementation? Although adding more protected areas is necessary, especially for underprotected ecosystems, it is fundamental to develop effective management for fully implementation of PAs in order to meet conservation goals and targets. This information should be orientating the decision-making process in the future, not only in Chile, but in countries facing similar challenges.

\section{Additional file}

Additional file 1: Chilean terrestrial and marine protected areas organized by region, protection category, management plan (MP) and management plan effectiveness. (DOCX 24 kb)

\footnotetext{
Abbreviations

CBD: Convention on Biological Diversity; CMPA: Coastal marine protected area; CONAF: National Forestry Service; EEZ: Exclusive economic zone; IUCN: International Union for Conservation of Nature; LSMPA: Large-scale marine protected area; MP: Marine park; MPA: Marine protected area; MR: Marine reserve; NGO: Non-governmental organization; NM: National monument; NR: National reserve; NS: Nature sanctuary; OECD: Organization for Economic Cooperation and Development; PA: Protected area; PAME: Protected Areas Management Effectiveness; SNASPE: Wild Protected Areas National System; SUBPESCA: Undersecretary of Fisheries;
}

UNCED: United Nations Conference on Environment and Development WCPA: World Commission on Protected Area

\section{Acknowledgments}

We wish to thank CONAF (National Forestry Service) for providing key information for the development of this study and to the anonymous reviewers for their useful commentaries. This article was written as part of the "Socioecology and Conservation Biology" class in the "Applied Biology and Ecology" cooperative PhD program of Universidad Católica del Norte and Universidad de La Serena, Chile. This article is in memory of Eric José Petit Díaz.

\section{Funding}

The Millennium Science Initiative, ESMOI, supported the analysis and writing work Comisión Nacional de Investigación Científica y Tecnológica (CONICYT), grants n 21170577 and $n^{\circ} 21170169$ supported data gathering and writing work.

\section{Availability of data and materials}

Not applicable.

\section{Authors' contributions}

IJP, ANC and MJH: Data collection, analysis and manuscript preparation. CFG and FAS: discussion, manuscript preparation and revision. All authors read and approved the final manuscript.

Ethics approval and consent to participate

Not applicable.

\section{Consent for publication}

Not applicable.

\section{Competing interests}

The authors declare that they have no competing interests.

\section{Publisher's Note}

Springer Nature remains neutral with regard to jurisdictional claims in published maps and institutional affiliations.

\section{Author details}

${ }^{1}$ Departamento de Biología Marina, Universidad Católica del Norte, Larrondo 1281, Coquimbo, Chile. ²Departamento de Ciencias Biomédicas, Facultad de Medicina, Universidad Católica del Norte, Larrondo 1281, Coquimbo, Chile. ${ }^{3}$ Departamento de Biología, Facultad de Ciencias, Universidad de La Serena, Benavente 980, La Serena, Chile. ${ }^{4}$ Millennium Nucleus for Ecology and Sustainable Management of Oceanic Islands (ESMOI), Coquimbo, Chile. ${ }^{5}$ Centro de Estudios Avanzados en Zonas Áridas (CEAZA), Coquimbo, Chile. ${ }^{6}$ Instituto de Ecología y Biodiversidad (IEB), La Serena, Chile.

Received: 10 October 2017 Accepted: 17 January 2018

Published online: 30 January 2018

\section{References}

1. Batista MI, Cabral HN. An overview of marine protected areas in SW Europe: factors contributing to their management effectiveness. Ocean Coast Manag. 2016;132:15-23.

2. Bonham CA, Sacayon E, Tzi E. Protecting imperiled "paper parks": potential lessons from the Sierra Chinajá, Guatemala. Biodivers Conserv. 2008;17:1581-93.

3. Cárcamo PF, et al. Opportunities and constraints of the institutional framework for the implementation of an ecosystem-based management: The case of the Chilean coast. Ocean Coast Manag. 2013;84:193-203.

4. Cbd.int. Biodiversity Target. 2010. https://www.cbd.int/2010-target. Accessed 10 May 2017

5. Census.gov. International Programs-People and Households - U.S. Census Bureau. 2017. https://www.census.gov/programs-surveys/internationalprograms.html. Accessed 18 Jan 2018.

6. Coad L, et al. Measuring impact of protected area management interventions: current and future use of the Global Database of Protected Area Management Effectiveness. Phil Trans R Soc B. 2015;370:20140281.

7. Figueroa E. Diseño operativo de una estrategia de financiamiento de mediano y largo plazo del sistema nacional de áreas protegidas de chile. Informe Final Proyecto N 59602, PNUD, Creación de un Sistema Nacional 
Integral de Áreas Protegidas para Chile: Estructura Financiera y Operacional; 2012. p. 231.

8. Gaymer CF, et al. Diagnóstico implementación reserva marina I. Choros La Hiquera. Informe Final - Etapa III: Plan de Administración para la Reserva Marina Islas Choros-Damas. Código BIP-30006824-0. 2007:139.

9. Gaymer CF, et al. Bases técnicas para la gestión del Parque Marino NazcaDesventuradas y propuesta de Plan General de Administración. Informe final proyecto FIPA 2016-31. 2018.

10. Gill DA, et al. Capacity shortfalls hinder the performance of marine protected areas globally. Nature. 2017;543(7647):665-9.

11. Govan H. Achieving the potential of locally managed marine areas in the South Pacific. SPC Traditional Marine Resource Management and Knowledge Information Bulletin. 2009;25:16-25.

12. Hilborn R. Marine biodiversity needs more than protection. Nat News. 2016; 535(7611):234-6.

13. Hockings, $M$ et al. Evaluating effectiveness: A framework for assessing management effectiveness of protected areas. 2nd ed. Best Practice Protected Area Guidelines Series No. 14; 2006.

14. Islam GMN, et al. Community perspectives of governance for effective management of marine protected areas in Malaysia. Ocean Coast Manag. 2017;135:34-42.

15. Jones PJS, De Santo EM. Viewpoint - is the race for remote, very large marine protected areas (VLMPAs) taking us down the wrong track? Mar Policy. 2016;73:231-4.

16. Jorquera-Jaramillo C, et al. Conservación de la biodiversidad en Chile: Nuevos desafíos y oportunidades en ecosistemas terrestres y marinos costeros. Rev Chil Hist Nat. 2012;85:105.

17. Juffe-Bignoli D, et al. Protected planet report. Cambridge: UNEP-WCMC; 2014

18. Klein, CJ et al. Shortfalls in the global protected area network at representing marine biodiversity. Nature Publishing Group; 2014:1-7.

19. Leenhardt $P$, et al. The rise of large-scale marine protected areas: conservation or geopolitics? Ocean Coast Manag. 2013;85:112-8.

20. Leverington $\mathrm{F}$, et al. A global analysis of protected area management effectiveness. Environ Manag. 2010;46(5):685-98.

21. Lewis N, et al. Large-Scale Marine Protected Areas: Guidelines for design and management. Best Practice Protected Area Guidelines Series, No. 26. Gland: IUCN; 2017. xxviii + 120

22. Mahajan SL, Daw T. Perceptions of ecosystem services and benefits to human well-being from community-based marine protected areas in Kenya. Mar Policy. 2016;74:108-19.

23. Martinez-Tillería, K. Optimización de un portafolio de conservación marinoterrestre para Chile: efectos y consecuencias de la integración. PhD Thesis, Programa de Doctorado en Biología y Ecología Aplicada, Universidad de La Serena \& Universidad Católica del Norte, La Serena, Chile. 2015:377.

24. Margules R, et al. Systematic conservation planning. Nature. 2000;405:243-53.

25. Ministerio de Medio Ambiente. Las áreas protegidas de Chile 2015. Andros, Chile. 2015: 68p.

26. Myers N, et al. Biodiversity hotspots for conservation priorities. Nature. 2000; 403(6772):853-8.

27. Pascual $\mathrm{M}$, et al. Socioeconomic impacts of marine protected areas in the Mediterranean and Black Seas. Ocean Coast Manag. 2016;133:1-10.

28. Pauly D et al. Fishing down marine food webs. Science. 1998;279:860-863.

29. Rocliffe $\mathrm{S}$, et al. Towards a network of locally managed marine areas (Immas) in the western Indian Ocean. PLoS One. 2014;9(7):e103000.

30. Saout SL, et al. Protected areas and effective biodiversity conservation Science. 2013;342:803-5.

31. Sodhi, NS \& Ehrlich, PR, Conservation Biology for All, 2010. 360p.

32. Squeo $\mathrm{F}$, et al. Towards the creation of an integrated system of protected areas in Chile: achievements and challenges. Plant Ecol Divers. 2012;5(2):1-11.

33. Toonen RJ, et al. One size does not fit all: the emerging frontier in largescale marine conservation. Mar Pollut Bull. 2013;77(1-2):7-10.

34. UNEP-WCMC \& IUCN. Protected Planet Report 2016. UNEP-WCMC and IUCN: Cambridge UK and Gland, Switzerland. 2016.

35. Waldron A, et al. Targeting global conservation funding to limit immediate biodiversity declines. Proc Natl Acad Sci. 2013;110(29):1-5.

36. Wilhelm TA, Sheppard CR, Sheppard AL, Gaymer CF, Parks J, Wagner D, Lewis N. Large marine protected areas-advantages and challenges of going big. Aquatic Conserv: Mar Freshw Ecosyst. 2014;24(S2):24-30.

\section{Submit your next manuscript to BioMed Central and we will help you at every step:}

- We accept pre-submission inquiries

- Our selector tool helps you to find the most relevant journal

- We provide round the clock customer support

- Convenient online submission

- Thorough peer review

- Inclusion in PubMed and all major indexing services

- Maximum visibility for your research

Submit your manuscript at www.biomedcentral.com/submit
Biomed Central 